\title{
Field-based Evidence of the Black Coffee Twig Borer infesting Maesopsis eminii in Coffee Agro-systems in Kiboga District, Uganda
}

\author{
Kagezi, G. H. ${ }^{1, *}$, Kucel P. ${ }^{1}$, Nakibuule L. ${ }^{1}$, Kobusinge J. ${ }^{1}$, Katondi, A. P. ${ }^{1}$, Wagoire, W. W. ${ }^{1}$ \\ ${ }^{1}$ National Coffee Research Institute (NaCORI), National Agricultural Research Organisation. \\ *Corresponding author. $\square 185$ Mukono, Uganda @ gkagezi@naro.go.ug
}

\begin{abstract}
Despite Ugandan coffee farmers' preference for Maesopsis eminii as a shade tree, the species is an alternate host for the black coffee twig borer, Xylosandrus compactus (Eichhoff) - a major insect pest of coffee in the country. Wilting and drying of leaves and branches of young $M$. eminii trees $(<5 \mathrm{~m}$ tall) observed in Kiboga District, Uganda. The branches were trimmed off the trees, separated into primary and secondary branches and then the percentage of those possessing characteristic $X$. compactus entry holes determined separately. Additionally, the number of entry holes on both primary and secondly branches was established to determine the extent of damage of $X$. compactus. $X$. compactus characteristic holes were observed on both primary and secondary branches of $M$. eminii - percentage of branches having entry holes and the number of entry holes higher on primary than secondary branches. Dissecting the branches at the entry holes revealed various life stages of X.compactus in the gallery, proving that the damage was due to the pest. Presence of this pest on trees that are inter-planted in the coffee agroforestry systems presents a dilemma in managing it. Therefore, research should be geared towards designing management strategies for the pest in the coffee agroforestry systems. In the meantime, farmers should always trim-off and burn all infested parts from coffee and other plants inter-planted in it.
\end{abstract}

Keywords: Agroforestry-systems, alternative-hosts, coffee, insect-pests.

\section{Introduction}

Traditionally, farmers in Uganda often deliberately plant and/or maintain naturally established trees in their coffee plantations. Similarly, modern research and extension promote and encourage farmers to plant trees in their coffee plantations to form coffee agroforestry systems (Kiyingi and Gwali, 2012; Kalanzi and Nansereko, 2014). These agroforestry systems are particularly for shade (Beer, 1987), but can also be utilized for other socio-economic benefits (Kiyingi and Gwali, 2012). Agroforestry has therefore emerged as a promising land-use option to sustainable agricultural productivity and livelihoods of farmers (Syampunani et al., 2010).

One of the commonest trees inter-planted with coffee in Uganda is the umbrella tree, Maesopsis eminii (Engl.), locally known by its Luganda name 'musizi' (Kalanzi and Nansereko, 
2014). The popularity of this tree species is attributed to its fast growth, readily available planting materials and ease of propagation. In addition, its leaves decompose easily and it is compatible with existing agricultural practices (Hall, 1995). M. eminii also provides additional products such as timber and firewood (Kalanzi and Nansereko, 2014).

Despite farmers' preference for inter-planting $M$. eminii in their coffee, screen-house experiments at the National Coffee Research Institute (NaCORI), Kituza, Uganda have confirmed an alternate host of the black coffee twig borer, Xylosandrus compactus (Eichhoff) (Kagezi et al., 2013, 2016b). X. compactus is currently one of the most important pests infesting coffee as well as other commercial crops like cocoa in Uganda (Kagezi et al., 2014; 2016a). The presence of $X$. compactus on $M$. eminii as well as other shade tree species inter-planted in coffee and cocoa (Kagezi et al., 2013) therefore, presents a dilemma in managing this pest.

Though, evidence of $X$. compactus infesting $M$. eminii under screen-house conditions exists (Kagezi et al., 2013), no study has been done to prove this under field conditions. This research note therefore provides for the first time field-based evidence that $M$. eminii is an alternative host of $X$. compactus. This information is vital for designing management strategies for $X$. compactus in coffee agroforestry systems.

\section{Materials and Methods}

Data presented herein were collected from a farmer's coffee field located in Kawanda village, Lwamata sub-county, Kiboga district, Uganda. Kiboga district lies between $11^{\circ} 30^{\circ e} \mathrm{~N}$ and $32^{\circ}$ $14^{\text {ee }} \mathrm{E}$ at $1000-1200 \mathrm{~m}$ above sea level (a.s.l) (KDLG 2012). The area has a mean annual temperature of about $25^{\circ} \mathrm{C}$ and receives a total annual rainfall of $1000-1400 \mathrm{~mm}$ that is distributed in a bimodal pattern. Its soils are classified as Ferralsols and characterized by soil fertility limitations such as low $\mathrm{pH}$, phosphorus and cation exchange capacity (Musinguzi et al. 2015). While conducting studies on the bio-ecology of $X$. compactus in Kiboga district, the $\mathrm{NaCORI}$ research team observed wilting and drying of small branches of the young $M$. eminii $(<5 \mathrm{~m}$ tall) trees (Figure 1$)$.

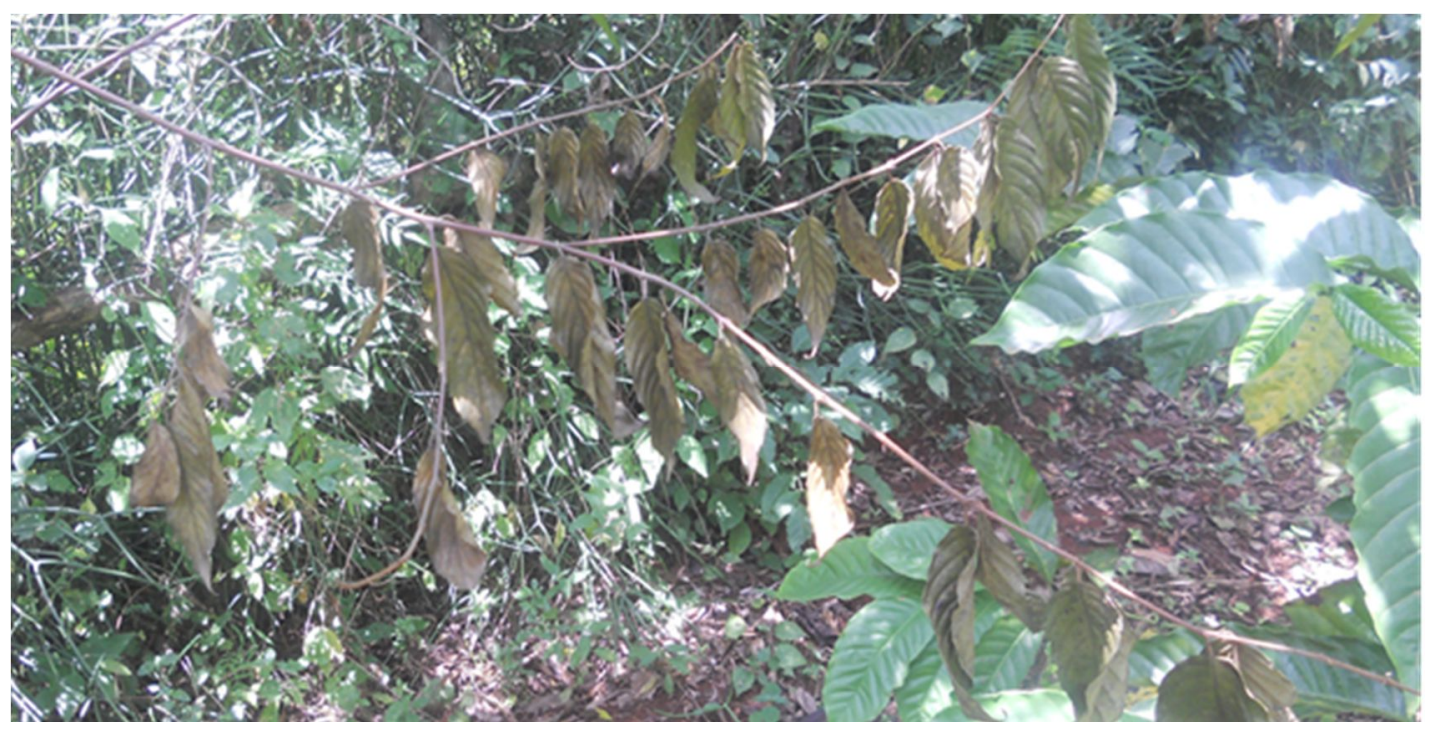

Figure 1. Branches of Maesopsis eminii tree species infested with Xylosandrus compactus 
The cause of this wilting and drying was suspected to be damage due to X. compactus (Kagezi et al., 2013, 2016a). These branches were therefore cut off from the trees using secateurs, separated into primary $(n=13)$ and secondary $(n=25)$ branches and then assessed for $X$. compactus damage separately. $X$. compactus infestation was assessed by determining the percentage of those branches that had the characteristic entry holes (Greco and Wright, 2015). In addition, the number of $X$. compactus entry holes on each branch was established in order to determine the extent of the infestation. To prove that this damage was caused by $X$. compactus, the infested branches were dissected at the characteristic entry hole to observe presence of life stages of the beetle in the gallery (Figure 2).

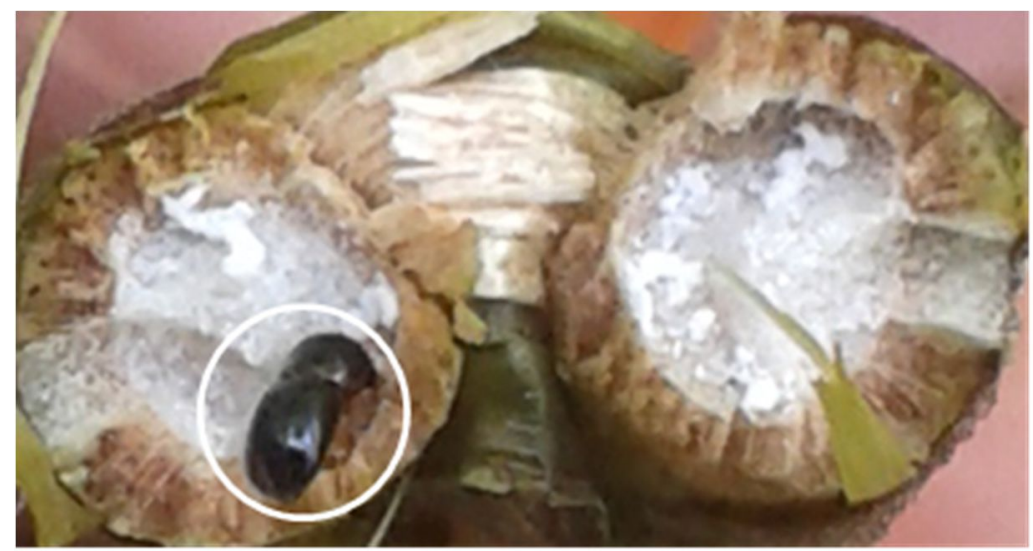

Figure 2. A broken primary branch of Maesopsis eminii with adult Xylosandrus compactus (circled) inside the galleries

Chi-square analysis using SAS (SAS Institute, 2008) was performed to compare the percentage of primary and secondary branches infested by $X$. compactus as well as the number of characteristic entry holes on the primary and secondary branches.

\section{Results}

$X$. compactus characteristic holes were observed on both primary and secondary branches of $M$. eminii. The percentage of primary branches with $X$. compactus entry holes $(92.3 \%$; $=13)$ was significantly $\left(\chi^{2}=53.7552 ; \mathrm{df}=1 ; \mathrm{p}<.0001\right)$ higher than secondary branches $(16.0 \% ; \mathrm{n}=25)$. Similarly, the number of $X$. compactus characteristic entry holes observed on the wilting branches was significantly $(\chi 2=68.242 ; \mathrm{df}=1 ; \mathrm{p}<.0001)$ more on primary $(2.1 \pm 1.9$; range-1-8; $\mathrm{n}=13)$ than on secondary branches $(0.2 \pm 0.6$; range $=1-7 ; \mathrm{n}=25)$. Dissecting the $M$. eminii branches at the entry holes revealed presence of various life stages of $X$. compactus (Fig. 2).

\section{Discussion}

Our results confirmed that the extensive wilting and drying of leaves as well as primary and secondary branches observed on $M$. eminii was due to X. compuctus damage. This was evidenced 
by the presence of $X$. compactus characteristic entry holes on all the branches assessed as well as the various life stages of the pest observed inside the dissected branches (Kagezi et al., 2016b). These observations provide for the first time field-based evidence that $M$. eminii is an alternative host of $X$. compactus, supporting earlier screen-house experimental studies (Kagezi et al., 2013).

The percentage of branches that had been infested by $X$. compactus and the number of characteristic entry holes were significantly higher on primary than secondly branches. This is probably because most of the secondary branches were smaller than the preferred host plant diameter for oviposition by the female X. compactus (Greco and Wright, 2015), although, the diameters of the branches were not determined in this study. Generally, although, $X$. compactus is known to attack small twigs which are less than $20 \mathrm{~mm}$ in diameter (Hayato, 2007), the average diameter preferred by the beetle depends on the host plant species in question. For example, Greco and Wright (2015) observed that X. compactus had a preference of lateral branches of coffee in the range of 0.48 to $6.47 \mathrm{~mm}$ (average $3.09 \mathrm{~mm}$ ). In Croton reflexifolius $\mathrm{HBK}$ and Acacia koa Gray, the diameter of the branches ranged from 2.5 to $15 \mathrm{~mm}$ (Hara and Beardsley, 1979) whereas, diameters of 1-7 $\mathrm{mm}$ and 8-22 $\mathrm{mm}$ of small and larger branches respectively, were observed on flowering dogwood twigs (Ngoan et al., 1976).

The presence of $X$. compactus on plants such as $M$. eminii which are inter-planted in coffee by farmers (Kalanzi and Nansereko, 2014), presents pest management implications in a number of ways. First of all, the extent of damage on coffee has been reported to be related to its proximity to alternate host plants. This is further complicated by lack or limited sanitation of infested material on alternate within the plantations (Jones and Johnson 1996). Secondly, alternative hosts may influence the ecological dynamics (Tanwar et al., 2010) behaviour and biology of X. compactus (Jones et al., 1992; Kagezi et al., 2013). Thirdly, farmers may need to choose between protecting their coffee from $X$. compactus infestation by eliminating the alternate hosts or maintaining them for other purposes (Kagezi et al., 2013) such as timber and firewood (Kalanzi and Nansereko, 2014). Lastly, the big size of some alternate plant hosts like M. eminii might complicate managing $X$. compactus by using the current recommended option of trimming-off and burning of infested plant materials (Kagezi et al., 2016a).

\section{Conclusion}

This is the first field-based evidence that $X$. compactus infests $M$. eminii, adding to the existing list of alternative hosts of this pest that have been confirmed in the coffee agro-systems. This presents a management dilemma of this pest in these systems. Research should therefore embark on designing management strategies for this pest in such an agroforestry system. However, in the meantime, farmers should always trim-off and burn all X. compactus-infested parts from not only coffee but also other plants inter-planted in it.

\section{Acknowledgements}

This study was funded by the World Bank through the Agricultural Technology and Agribusiness Advisory Services (ATAAS) project. We also acknowledge the contribution of V. Kigonya and R. Nseranyi during data collection as well as Lieutenant William Ssempebwa (Retired) of Kiboga District for allowing us to use his farm. 


\section{References}

Beer, J. 1987. Advantages, disadvantages and desirable characteristics of shade trees for coffee, cocoa and tea. Agroforestry Systems 5:3-13.

Greco, E.B. and Wright, M.G. 2015. Ecology, biology and management of the black twig borer (Coleoptera: Curculionidae: Scolytinae) with emphasis on coffee in Hawaii. Journal of Integrated Pest Management 6(1)7;DOI:10.1093/jipm/pmv007.

Hall, J.B. 1995. Maesopsis eminii and its status at Amani. Report to the East Usambara Catchment Forest Project, pp. 37.

Hara, A.H., and Beardsley, J.W. Jr. 1979. The biology of the black twig borer, Xylosandrus compactus (Eichhoff), in Hawaii. Proceedings of the Hawaiian Entomological Society 18: 5570.

Hayato, M. 2007. Note on the dieback of Cornus Florida caused by Xylosandrus compactus. . Bulletin of Forestry and Forest Products Research Institute 6:59-63.

Jones, V.P. and Johnson. M.W. 1996. Management of black twig borer on coffee. GACC Termination report, p. 6.

Jones, V.P., Burnam-Larish, LL. and Caprio, LC. 1992. Effect of harvest interval and cultivar on damage to macadamia nuts caused by Hypothenemus obscurus (Coleoptera: Scolytidae). J. Economic Entomology 85:1878-1883.

Kagezi, G.H., Kucel P., Nakibuule, L., Kobusinge, J., Ahumuza, G. and Wagoire, W.W. 2016 a. Current research status and strategic challenges on the black coffee twig borer, Xylosandrus compactus in Uganda. 2nd Scientific Conference on African Coffee. The Inter African Coffee Organisation (IACO) 56th Annual General Assembly, November 28 - December 3, 2016, Yaoundé, Cameroon.

Kagezi, G.H., Kucel, P., Egonyu, J.P., Ahumuza, G., Nakibuule, L., Kobusinge, J. and Wagoire, W.W. 2014. Implications of Black Coffee Twig Borer on cocoa in Uganda. Uganda Journal of Agricultural Sciences 15(2):179-189.

Kagezi, G.H., Kucel, P., Mukasa, D., van Asten, P., Musoli, P.C. and Kangire, A. 2013. Preliminary report on the status and host plant utilization by the Black Coffee Twig Borer, Xylosandrus compactus (Eichhoff) (Coleoptera: Curculionidae) in Uganda. Proceedings of the $24^{\text {th }}$ International Conference on Coffee Science, ASIC, San José, Costa Rica November 11 16, 2012. Pp. 1323-1326.

Kagezi, G.H., Kucel, P., Nakibuule, L., Kobusinge, J., Katondi, A. 2016b. Back to office report: BCTB field diagnostic studies in Greater Mubende sub-region (Mubende, Mityana, Kiboga and Kyankwanzi districts). Submitted to NaCORI/NARO.

Kalanzi, F. and Nansereko, S. 2014. Exploration of farmers' tree species selection for coffee agroforestry in Bukomansimbi district of Uganda. International Journal of Research on Land-use Sustainability 1:9-17.

KDLG, 2011. Sub-county Development Programme. Implementation of the community information system (CIS). Kiboga District Local Government report based on CIS summery results 2009. Vol. I. www.ubos.org/onlinefiles/uploads/.../CIS.../CIS\%20summary $\% 20$ reports/Kiboga.pdf. Last accessed on July 10, 2015.

Kiyingi, I. and S. Gwali, S. 2012. Productivity and profitability of Robusta coffee agroforestry systems in central Uganda. Uganda Journal of Agricultural Sciences 13(1):85-93.

Musinguzi, P., Ebanyat, P., Tenywa, J.S., Basamba, T.A., Tenywa, M.M. and Mubiru, D. 2015. Precision of farmer-based fertility ratings and soil organic carbon for crop production on a Ferralsol. Solid Earth 6:1063-1073. 
Ngoan, N.D., Wilkinson, R.C., Short, D.E., Moses, C.S. and Mangold, J.R. 1976. Biology of an introduced ambrosia beetle, Xylosandrus compactus in Florida. Annals of the Entomological Society of America 69: 872-876.

SAS Institute. 2008. SAS/STAT Software: Version 9.2, SAS Institute Inc., SAS Campus Drive, Cary, North Carolina 27513.

Syampunani, S., Chirwa, P.W., Akinnifest, F.K. and Ajayi, O.C. 2010. The potential of using agroforestry as a win-win solution to climate change mitigation and adaptation and meeting food security challenges in Southern Africa. Agricultural Journal 5:80-88.

Tanwar, R.K., Jeyakumar P. and Vennila, S. 2010. Papaya mealy bug and its management strategies. Technical Bulletin 22, National Centre for Integrated Pest Management, New Delhi. 